\title{
FENOLOGIA DE Tapirira guianensis AUBL. (Anacardiaceae) NO MUNICÍPIO DE SÃO CRISTÓVÃO, SERGIPE ${ }^{1}$
}

\author{
Paula Luíza Santos² e Robério Anastácio Ferreira ${ }^{3}$
}

\begin{abstract}
RESUMO - Realizou-se um estudo fenológico de Tapirira guianensis Aubl. no Campus da Universidade Federal de Sergipe, Município de São Cristóvão (1055'32"S e 3706’08"W), com o intuito de obter informações sobre o comportamento dessa espécie. Foram observados 21 indivíduos em intervalos quinzenais, durante 30 meses, sendo analisados seus parâmetros fenológicos reprodutivos e vegetativos, por meio da porcentagem de indivíduos e percentual de intensidade de Fournier. T. guianensis apresentou floração na transição da estação seca para a chuvosa (outubro-maio), produção de frutos na época seca (dezembro-junho) com maturação no início das chuvas (maio-julho) e brotamento e queda de folhas contínuos ao longo do ano. Observou-se padrão sazonal anual de floração e frutificação na espécie.
\end{abstract}

Palavras-chave: Floração, Frutificação, Pau-pombo, Mudança foliar.

\section{PHENOLOGY OF Tapirira guianensis AUBL. (Anacardiaceae) IN SÃO CRISTÓVÃO, SERGIPE, BRAZIL}

\begin{abstract}
A phenologic study of Tapirira guianensis Aubl. was carried out in the Campus of the Universidade

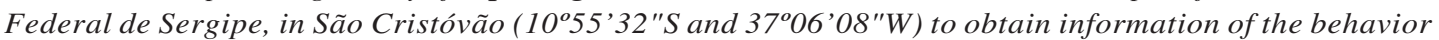
of this species. Twenty-one individuals were observed at fortnight intervals for 30 months. The following parameters were analyzed: percentage of individuals and Fournier intensity percentage. T. guianensis showed flowering in the transition of the dry to the rain season (October-May), fruit production in the dry season (DecemberJune) with maturation in the early rain season (May-July). The brushing and fall of leaves were constant over the year. It was observed an annual seasonal pattern of flowering and fruiting.
\end{abstract}

Keywords: Flowering, Fruit production, Pau-pombo, Leaf changes.

\section{INTRODUÇÃO}

Nas regiões tropicais, os fatores climáticos e as interações entre espécies estão frequentemente relacionados com a sazonalidade dos eventos fenológicos nas plantas, tanto sob o aspecto de comunidade (BENCKE; MORELLATO, 2002; MANTOVANI et al., 2003; ANDREIS et al., 2005) quanto de espécie (PEDRONI et al., 2002; BIANCHINI et al., 2006). Quando realizada de forma sistemática, a observação fenológica reúne informações sobre o estabelecimento das espécies, períodos de crescimento e reprodução e disponibilidade de recursos alimentares, que podem estar associados a mudanças na qualidade e na quantidade de recursos abióticos (MORELLATO; LEITÃO-FILHO, 1992).

Pires-O'Brien e O'Brien (1995) enfatizaram que vegetações com climas mais sazonais apresentam maior periodicidade na produção de flores, folhas e frutos, sendo a alternância das estações seca e úmida apontada como o principal fator envolvido no desencadeamento das fenofases. Nas florestas tropicais, são encontradas espécies florescendo e frutificando o ano todo. Porém, o número de espécies produzindo flores e frutos varia ao longo do ano,

\footnotetext{
${ }^{1}$ Recebido em 11.01.2010 aceito para publicação em 17.01.2013.

${ }^{2}$ Centro Comunitário de Formação em Agropecuária Dom José Brandão de Castro-CFAC. E-mail: <p.luizas @ gmail.com>.

${ }^{3}$ Universidade Federal de Sergipe. E-mail: <raf@infonet.com.br>.
} 
estando essa variação relacionada aos fatores ambientais, principalmente à precipitação (MORELLATO; LEITÃO-FILHO, 1992).

Eventos fenológicos reprodutivos sazonais e sincronizados podem representar vantagens adaptativas para muitas espécies tropicais (PEDRONI et al., 2002). Wright e Van Schaik (1994) afirmaram que algumas plantas iniciam a produção de flores estimuladas pela variação sazonal na irradiação solar e apresentam frutos maduros no final da estação seca e início da estação chuvosa, o que proporciona maiores chances de sobrevivência às plântulas (VAN SCHAIK et al., 1993).

Em florestas tropicais, o brotamento e queda de folhas podem ocorrer em qualquer época do ano, sendo sazonais em algumas espécies. Apenas em climas não sazonais mais extremos a mudança foliar é contínua (RICHARDS, 1996). A queda gradual de folhas durante o ano pode ser resultante da senescência natural ou adaptação da espécie para a economia de água, que com o início da estação seca perde suas folhas (SANTOS; TAKAKI, 2005). Bianchini et al. (2006) observaram que a queda de folhas em Chrysophyllum gonocarpum (Mart. \& Eichler) Engl., numa Floresta Semidecídua no Sul do Brasil, provavelmente foi resultante do estresse hídrico. Já Pedroni et al. (2002), estudando a fenologia de Copaifera langsdorffii Desf. no Município de Campinas, SP, observaram que a precipitação, após período de estresse hídrico, foi o principal fator de estímulo para o brotamento.

As observações fenológicas são importantes dos pontos de vista botânico e ecológico, contribuindo direta ou indiretamente para o desenvolvimento e compreensão de projetos e pesquisas na área florestal, tornando-se ferramenta fundamental em programas de manejo e recomposição de áreas degradadas e ciliares.

Tapirira guianensis Aubl., conhecida popularmente como pau-pombo, é considerada a espécie nativa mais comum da família Anacardiaceae, ocorrendo em quase todas as formações florestais do Brasil (SOUZA; LORENZI, 2005). Segundo Lorenzi (2002), trata-se de uma árvore perenifólia, pioneira e heliófita, que mede 8-14 m de altura e ocorre em todo o território brasileiro, sendo bastante encontrada em formações secundárias de solos úmidos, como os de várzeas e beira de rios, podendo ser encontrada também em ambientes secos de encosta. Ainda segundo esse autor, a espécie apresenta grande potencial para ser utilizada em programas de recuperação de áreas degradadas, principalmente em locais úmidos, por ser tolerante a esse ambiente e por produzir frutos altamente procurados pela fauna.

O comportamento fenológico de T. guianensis ainda não foi caracterizado no Estado de Sergipe, além de existirem diferenças entre as fenofases e poucas informações sobre esse assunto em espécies florestais da Região Nordeste. Nesse aspecto, este trabalho foi realizado com o objetivo de fornecer informações básicas sobre o comportamento dessa espécie e sua relação com o clima, em uma área do Município de São Cristóvão, SE, visando subsidiar programas de produção e colheita de sementes e recuperação de ambientes degradados.

\section{MATERIAL E MÉTODOS}

\section{1. Área de estudo}

O trabalho foi realizado no Campus da Universidade Federal de Sergipe (UFS), localizado no Município de São Cristóvão (1055'32"S e 3706'08"W), com altitude aproximada de $47 \mathrm{~m}$. O Campus da UFS está situado em área de domínio de Mata Atlântica e abriga alguns remanescentes de vegetação florestal. O clima de região é do tipo As, ou seja, tropical chuvoso com verão seco, de acordo com a classificação de Köppen. O período chuvoso ocorre entre os meses de abril e agosto, a temperatura média na região é de $25^{\circ} \mathrm{C}$, a umidade relativa do ar média é de $75 \%$ e a precipitação média anual é de $1.200 \mathrm{~mm}$ (MELO et al., 2006).

\subsection{Seleção dos indivíduos}

Os indivíduos de T. guianensis foram selecionados de forma aleatória, considerando-se uma distância média de $50 \mathrm{~m}$ entre eles, na tentativa de assegurar uma maior variabilidade genética entre os indivíduos (KAGEYAMA; GANDARA, 1999). A seleção foi realizada com base na altura das plantas, diâmetro à altura do peito (DAP) e aspectos fitossanitários.

Os indivíduos selecionados foram georreferenciados (GPS-Garmin 12), etiquetados com placas de alumínio $(4,5 \times 5,0 \mathrm{~cm})$ e caracterizados fenotipicamente em relação ao DAP, área de copa e altura. Em campo, mediu-se o DAP com o auxílio de uma fita diamétrica (Diameter Tape 7,5 m) a 1,30 m do solo; a área de copa foi medida em duas posições (Norte-Sul e Leste-Oeste) com um diastímetro $(50 \mathrm{~m})$, e a altura foi medida com o auxílio de um clinômetro (Haglöf Electronic Clinometer). 


\subsection{Observações fenológicas}

As observações fenológicas dos indivíduos tiveram início em janeiro de 2005, sendo realizadas a cada 15 dias, até junho de 2007, com o auxílio de um binóculo (Zenit Lente Rubi 8-24x50). Os eventos fenológicos acompanhados foram: floração, frutificação e mudança foliar, sendo cada fase caracterizada da seguinte maneira: a) Floração - evento qualificado conforme sua progressão em dois estádios: botões florais e antese (flores abertas); b) Frutificação - evento qualificado em dois estádios: frutos novos e frutos maduros; e c) Mudança foliar sendo observados os estádios de brotação e queda foliar.

\subsection{Análise dos dados}

Foram utilizados dois métodos de avaliação para analisar os indivíduos: a) Índice de atividade (ou porcentagem de indivíduos) que constata somente da presença ou ausência da fenofase em cada indivíduo, estimando-se também a sincronia entre os indivíduos da população, levando em consideração que, quanto maior o número de indivíduos manifestando a fenofase ao mesmo tempo, maior a sincronia da população. Foi considerado evento fenológico não sincrônico ou assincrônico para o valor $<20 \%$ de indivíduos na fenofase; pouco sincrônico ou sincronia baixa para valor de $20-60 \%$ de indivíduos na fenofase e sincronia alta para valor $>60 \%$ de indivíduos manifestando a fenofase (BENCKE; MORELLATO, 2002); eb) Percentual de Intensidade de Fournier (1974) que estima a intensidade de cada fenofase, por meio de uma escala intervalar semiquantitativa de cinco categorias (0 a 4), com amplitudes de $25 \%$ cada uma.

Para relacionar os padrões fenológicos com as variações ambientais, foram obtidas as precipitações mensais do período de observação e comparadas com a porcentagem de indivíduos da população que manifestaram determinada fenofase, bem como sua intensidade, ao longo do ano. Os dados de precipitação foram cedidos pelo Centro de Meteorologia e Recursos Hídricos do Estado de Sergipe (CMRH/SRH/SEMARH/ SE) e a partir deles, calculada a média mensal dos valores diários de precipitação, no período de observação.

\section{RESULTADOS}

No total foram selecionados 21 indivíduos de $T$. guianensis, que apresentaram altura variando de 8,70 a 23,80 m e média de $15,52 \mathrm{~m}$, DAP de 22,37 a 65,50 cm, média de 48,27 cm, área de copa de 113,11 a 539,15 $\mathrm{m}^{2}$ e média de $239,62 \mathrm{~m}^{2}$.

Com os valores descritos anteriormente, foi possível obter um perfil fenotípico para a espécie, uma vez que esse fator pode estar relacionado com os dados referentes à fenologia reprodutiva e vegetativa da população, já que, com os resultados, trata-se de indivíduos adultos, que podem ser utilizados como árvores matrizes para a colheita de sementes.

Os indivíduos de T. guianensis já estavam florindo, quando foi realizada a primeira avaliação em janeiro de 2005. Desse modo, a emissão de botões florais entre janeiro e março de 2005 e a antese entre os meses de janeiro e maio do respectivo ano correspondem à continuação do período reprodutivo do ano anterior (2004). Logo, no ano de 2005 a emissão de botões florais teve início em setembro, prolongando-se até maio de 2006, reiniciando o ciclo em setembro, estendendo-se até abril de 2007. A maior porcentagem de indivíduos com botões florais $(95,24 \%)$ ocorreu em dezembro de 2005 (Figura 1A). A antese teve início em novembro de 2005, prolongando-se até maio de 2006. Já em 2006 a antese teve início em outubro, estendendo-se até maio de 2007.

A intensidade de botões florais na população de T. guianensis (Figura 2A) foi maior em dezembro de 2005 , com $45,83 \%$ de botões e menor pico em abril de 2006 , com $7,74 \%$, correspondendo ao estádio final da fenofase. Já a antese apresentou picos em fevereiro de 2005, com 49,40\%; e janeiro de 2006, com 43,45\% das flores abertas. Os menores índices de flores abertas foram registrados em novembro de 2005, com 1,19\%; em outubro de 2006 , com $1,79 \%$; e abril de 2007 , com $1,19 \%$.

Em relação à floração e à ocorrência de chuvas na região, foi possível verificar que tanto a emissão de botões florais quanto a antese ocorreram desde a transição da estação chuvosa para a estação seca até o início da estação chuvosa seguinte.

Os indivíduos de T. guianensis já estavam também frutificando quando foi iniciada a avaliação (Figura 1B). A maior porcentagem de indivíduos com frutos verdes ocorreu em abril de 2005 (28,57\%), fevereiromarço de 2006 (30,95\%) e março-abril de 2007 (33,33\%), com picos em fevereiro de 2006 e março de 2007 (Figura 2B). Em 2005, a frutificação teve início em dezembro,

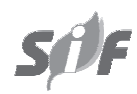

Revista Árvore, Viçosa-MG, v.37, n.1, p.129-136, 2013 
A

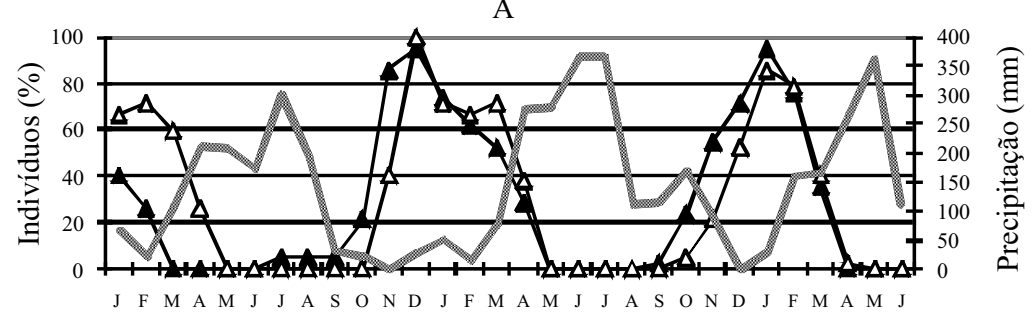

$\mathrm{B}$

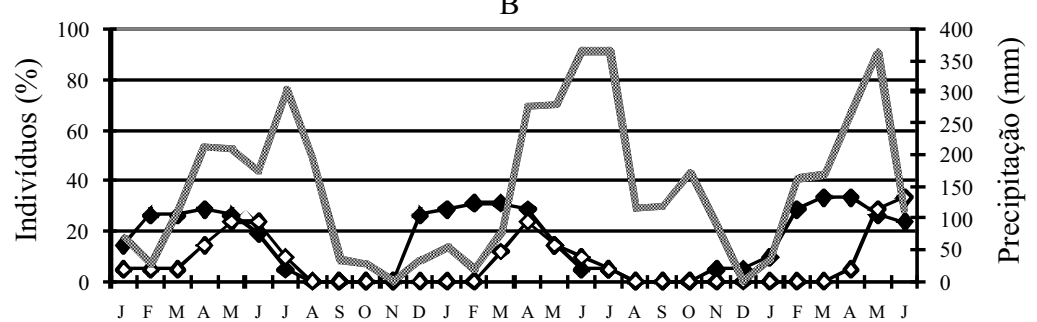

$\mathrm{C}$

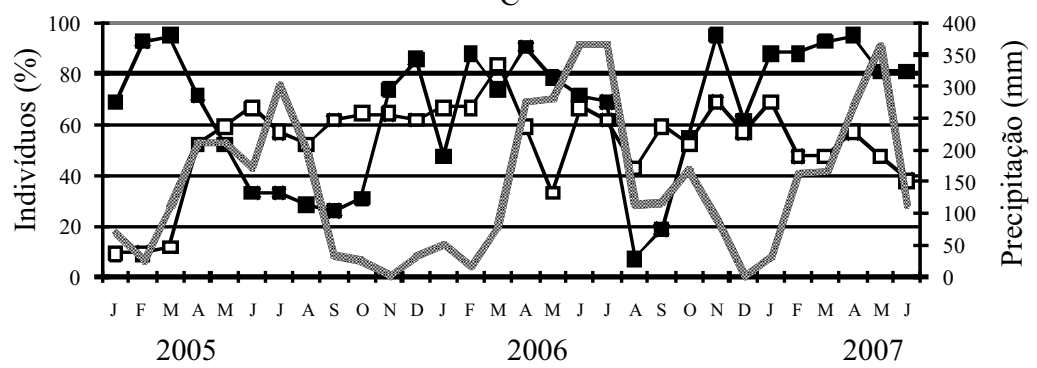

Figura 1 - Porcentagem de indivíduos de Tapirira guianensis em floração (A), frutificação (B) e mudança foliar (C), em estudo fenológico realizado no Município de São Cristóvão, SE. Legenda: $\boldsymbol{\Delta}=$ botões florais; $\Delta=$ flores; $\boldsymbol{\nabla}=$ frutos verdes; $\diamond=$ frutos maduros; $\boldsymbol{\|}$ = brotamento; $\square=$ queda de folhas; e linha = precipitação mensal.

Figure 1 - Percentage of individuals of Tapirira guianensis in flowering $(A)$, fruiting $(B)$ and leaf changing $(C)$ in phenologic study realized in the city of São Cristóvão-SE. Legend: $\mathbf{\Delta}=$ buds; $\Delta=$ flowers; $\diamond=$ green fruits; $\diamond=$ ripe fruits; $\mathbf{U}=$ shoots $; \mathbf{\square}=$ leaffall; and line = monthly precipitation .

prolongando-se até julho de 2006, recomeçando o ciclo três meses depois. A maturação dos frutos em 2005 teve início em janeiro, estendendo-se até o mês de julho, com 23,81\% dos indivíduos manifestando a fenofase. Em 2006, a maturação dos frutos teve início em março e prolongou-se até abril, com $23,81 \%$ dos indivíduos apresentando o fenômeno. Já em 2007 o amadurecimento dos frutos teve início em abril, com $33,33 \%$ dos indivíduos exibindo a fenofase.

A intensidade de frutos maduros teve picos em maio de 2005 (13,69\%), abril de 2006 (11,90\%) e junho de 2007 (16,67\%). Os menores índices de frutos maduros foram verificados entre janeiro e março de 2005, de maio a julho de 2006 e em abril de 2007 (Figura 2B).
A frutificação ocorreu na época seca no Município de São Cristóvão, Sergipe. Já a maturação ocorreu durante a estação chuvosa.

A queda de folhas em T. guianensis foi contínua ao longo do ano, com os indivíduos perdendo folhas, mas com pouca intensidade. A maior porcentagem de indivíduos com queda de folhas ocorreu em março de 2006, com 83,33\% da população exibindo o fenômeno (Figura 1C). A produção de folhas novas também foi contínua ao longo do ano, com maior porcentagem de indivíduos manifestando a fenofase em fevereiro e março de 2005 , com $92,86 \%$ e $95,24 \%$, respectivamente, e em novembro de 2006 e abril de 2007, com 95,24\% da população. A menor porcentagem de indivíduos em brotação foi registrada em agosto de 2006. 

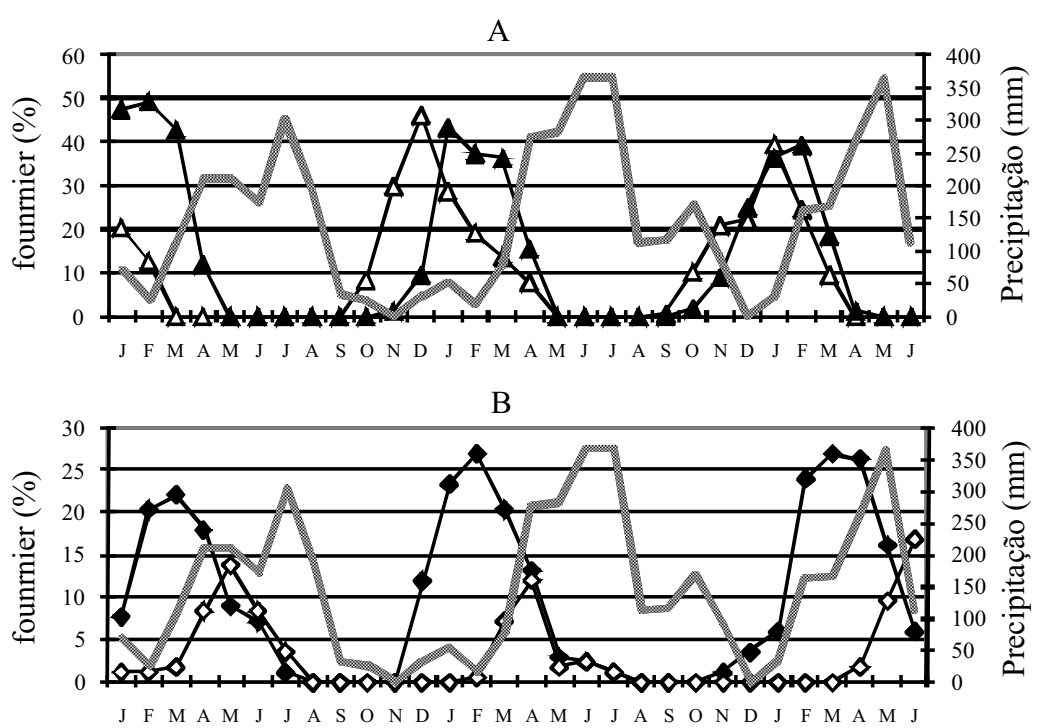

$\mathrm{C}$

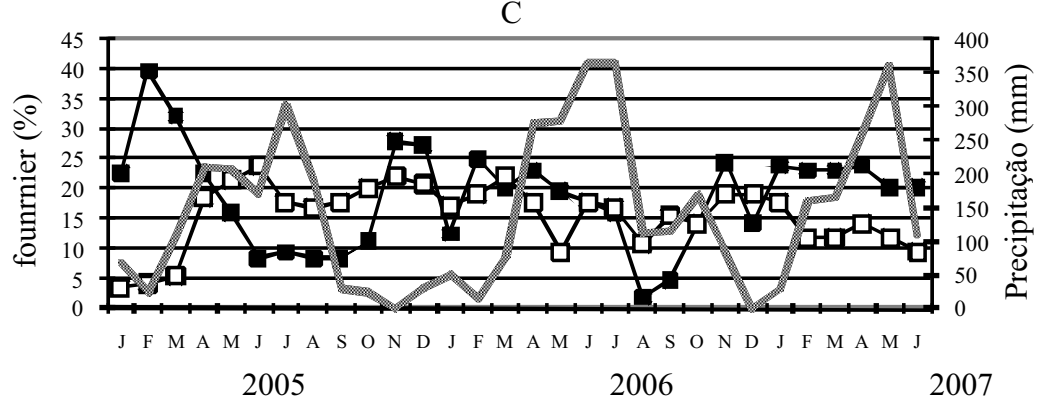

Figura 2 - Intensidade de Fournier na população de Tapirira guianensis para floração (A), frutificação (B) e mudança foliar (B), em estudo fenológico realizado no Município de São Cristóvão, SE. Legenda: $\boldsymbol{\Delta}=$ botões florais; $\boldsymbol{\Delta}=$ flores; $\diamond=$ frutos verdes; $\diamond=$ frutos maduros; $\boldsymbol{\|}=$ brotamento; $\square=$ queda de folhas; e linha = precipitação mensal. Figure 2 - Fournier intensity in the Tapirira guianensis population for flowering (A), fruiting (B) and leaf changing (C), in phenologic study realized in the city of São Cristóvão-SE. Legend: $\mathbf{\Delta}=$ buds; $\boldsymbol{\Delta}=$ flowers; $\boldsymbol{\nabla}=$ green fruits; $\diamond=$ ripe fruits; $\mathbf{\square}=$ shoots $; \square=$ leaffall $;$ and line = monthly precipitation .

A intensidade de queda foliar variou ao longo do ano (Figura 2C). Houve um período de alta intensidade de junho de 2005 a março de 2006 e de novembro de 2006 a janeiro de 2007 e um segundo período com baixa intensidade, de janeiro a março de 2005, janeiro, maio e agosto de 2006 e fevereiro a junho de 2007. Aintensidade de brotamento teve maior índice em fevereiro de 2005, com $39,88 \%$; e menor intensidade em agosto e setembro de 2006 , com $1,79 \%$ e $4,76 \%$, respectivamente.

\section{DISCUSSÃO}

A sincronia de floração dos indivíduos de $T$. guianensis, representada pela porcentagem de indivíduos que manifestaram o evento na população, pode ser classificada como alta, já que mais de $60 \%$ apresentaram fenofase (BENCKE; MORELLATO, 2002).

A população apresentou padrão de floração sazonal anual, de acordo com a classificação de Pires-O'Brien e O’Brien (1995). O evento durou cerca de oito meses na população, iniciando-se em outubro e estendendose até maio. Comportamento semelhante foi encontrado por Locatelli e Machado (2004), em uma área de Brejo de Altitude, em Pernambuco, onde a floração de $T$. guianensis ocorreu entre os meses de outubro a dezembro, correspondente à estação seca na região. De modo contrário, Lenza e Oliveira (2005), estudando a biologia 
reprodutiva da espécie em uma Mata de Galeria no Triângulo Mineiro, registraram a floração de T. guianensis no período de agosto a fevereiro, correspondente à estação chuvosa na região. Essa diferença na época de ocorrência do processo de floração em T. guianensis pode estar relacionada com os fatores ambientais característicos de cada região, ou fatores inerentes à própria espécie, como filogenia, síndrome de dispersão e atividades dos agentes polinizadores e dispersores de sementes (REYS et al., 2005).

Para Richards (1996), em ambientes tropicais sazonais, onde há uma estação seca definida, a maioria das espécies floresce nessa época. Já em regiões onde o clima é mais úmido e uniforme, como na Floresta Atlântica(BENCKE; MORELLATO, 2002; MANTOVANI et al., 2003; ANDREIS et al., 2005) e na Floresta Semidecídua (MORELLATO, 1992) do Sudeste do Brasil, o pico de floração ocorre na estação úmida. Mas em locais com fatores ambientais pouco sazonais, com climas uniformes, também há influência das variáveis climáticas sobre as fenofases das espécies, porém de maneira menos evidente do que em áreas cujo clima possui forte sazonalidade (LOCATELLI; MACHADO, 2004).

O padrão de frutificação em T. guianensis também foi sazonal, apresentando frutificação periódica anual, porém com baixa sincronia entre os indivíduos. O período de frutificação durou cerca de oito meses, iniciando em dezembro e finalizando em julho, com maturação dos frutos no período chuvoso. Na população estudada por Lenza e Oliveira (2005), em uma Mata de Galeria, no Triângulo Mineiro, os períodos de frutificação dessa espécie duraram seis meses em um (outubro de 1997 a março de 1998) e oito meses em outro (agosto de 1999 a março de 2000); e a maturação dos frutos ocorreu na estação chuvosa. Já Lorenzi (2002) mencionou que a maturação dos frutos em T. guianensis ocorre de janeiro a março.

Houve diferença na porcentagem de Fournier de frutos maduros em relação aos frutos verdes. O mesmo comportamento foi evidenciado por San Martin-Gajardo e Morellato (2003) e Lopes e Buzato (2005), em estudos com espécies da família Rubiaceae, em fragmentos de Mata Atlântica, no Estado de São Paulo. Segundo esses autores, essa diferença pode não ser resultante apenas da rápida remoção por animais frugívoros associada ao intervalo de observação, mas sim consequência do longo período necessário para maturação dos frutos, aumentando a proporção de frutos verdes em relação aos maduros.

Apesar de a população de T. guianensis apresentar elevada sincronia no processo de floração, a baixa sincronia na frutificação pode estar relacionada à dioicia da espécie, conforme apontado por Lenza e Oliveira (2005).

Com relação à frutificação e à precipitação no período estudado, o mesmo padrão foi encontrado por Locatelli e Machado (2004), trabalhando com espécies arbóreas em uma área de Brejos de Altitude em Pernambuco, onde as espécies zoocóricas, como é o caso de T. guianensis, frutificaram no final da estação seca e durante a estação chuvosa, quando as condições para germinação e crescimento das plântulas são mais propícias. Condição semelhante foi presenciada por Morellato e Leitão-Filho (1992) em estudo fenológico de espécies arbóreas em duas formações florestais na Serra do Japi, Estado de São Paulo; e por Amorim et al. (2009), em fenologia de espécies lenhosas numa comunidade arbórea da Caatinga do Seridó, no Rio Grande do Norte. Esse período de transição entre as estações proporcionaria maior probabilidade de as sementes receberem luminosidade e maior possibilidade de germinação e crescimento das plântulas devido à umidade, e estas teriam toda a estação chuvosa para desenvolver o sistema radicular antes da próxima estação seca (JANZEN, 1980).

A fenologia vegetativa de T. guianensis não apresentou padrão sazonal para a queda foliar. A maior intensidade de desfolhamento ocorreu na estação chuvosa, prolongando-se até a estação seca, tendo diminuição na estação chuvosa seguinte.

Em estudo sobre a fenologia de nove espécies arbóreas em três tipos de Floresta Atlântica, Bencke e Morellato (2002) não encontraram relação entre a queda foliar e a pluviosidade, visto que os indivíduos amostrados perderam folhas tanto no período superúmido quanto no período úmido. Padrão semelhante foi encontrado por Marques e Oliveira (2004) em duas Florestas de Restinga no Sul do Brasil, onde a queda de folhas das espécies ocorreu no final do período úmido e início do superúmido. Esses mesmos autores afirmaram ainda que esse padrão é pouco presenciado em florestas tropicais, e esse comportamento parece favorecer outros processos que ocorrem na floresta. Dias e Oliveira-Filho (1996) também presenciaram comportamento semelhante em 
indivíduos de Xilopia brasiliensis, que apresentaram pico de queda foliar no início do período chuvoso. Os referidos autores justificaram que o desfolhamento nessa espécie pode estar relacionado à disponibilidade de água em camadas mais profundas do solo e, dessa forma, o déficit hídrico na estação seca não teria afetado a reserva de água. Para Wright e Van Schaik (1994), o desencadeamento do processo da queda de folhas e de brotação em espécies tropicais está relacionado a mudanças no fotoperíodo.

T. guianensis é considerada perenifólia, por não apresentar queda de folhas concentrada em determinada época do ano e por produzir, de forma contínua, pequena quantidade de folhas novas anualmente. A sincronia de queda foliar e brotação foi considerada alta, já que mais de $60 \%$ da população exibiu o padrão de mudança foliar, como sugerido por Bencke e Morelllato (2002).

\section{CONCLUSÃO}

O estudo do comportamento fenológico da população de T. guianensis ao longo de 30 meses possibilita a identificação da ocorrência, intensidade e previsibilidade dos eventos reprodutivos e vegetativos dessa espécie no Estado de Sergipe, tornando-se possível estabelecer um cronograma de produção de sementes para estudos de fauna e programas de manejo e recomposição florestal.

\section{REFERÊNCIAS}

AMORIM, I. L.; SAMPAIO, E. V. S. B.; ARAÚJO, E. L. Fenologia de espécies lenhosas da caatinga do Seridó, RN. Revista Árvore, v.33, n.3, p.491-499, 2009.

ANDREIS, C. et al. Estudo fenológico em três fases sucessionais de uma floresta estacional decidual no município de Santa Tereza, RS, Brasil. Revista Árvore, v.29, n.1, p.55-63, 2005.

BENCKE, C. S. C.; MORELLATO, L. P. C. Estudo comparativo da fenologia de nove espécies arbóreas em três tipos de floresta atlântica no sudeste do Brasil. Revista Brasileira de Botânica, v.25, n.2, p.237-248, 2002.

BIANCHINI, E.; PIMENTEL, J. A.; SANTOS, F. A. M. Fenologia de Chrysophyllum gonocarpum (Mart. \& Eichler) Engl. (Sapotaceae) em floresta semidecídua do Sul do Brasil. Revista Brasileira de Botânica, v.29, n.4, p.595-602, 2006.
DIAS, H. C. T.; OLIVEIRA-FILHO, A. T. Fenologia de quatro espécies arbóreas de uma floresta estacional semidecídua montana em Lavras, MG. Cerne, v.2, n.1, p.66-88, 1996.

FOURNIER, L. A. Un método cuantitativo para la medición de características fenológicas em árboles. Turrialba, v.24, p.422-423, 1974.

JANZEN, D. H. Ecologia vegetal nos trópicos. São Paulo: EPU e Edusp, 1980. 79p.

KAGEYAMA, P. Y.; GANDARA, F. B.

Restauração, conservação genética e produção de sementes. In: SIMPÓSIO MATA CILIAR: CIỂNCIA E TECNOLOGIA, Lavras, 1999. Anais... Lavras: UFLA/FAEPE/CEMIG, 1999. p.59-68.

LENZA, E.; OLIVEIRA, P. E. Biologia reprodutiva de Tapirira guianensis Aubl. (Anacardiaceae), uma espécie dióica em mata de galeria do Triângulo Mineiro, Brasil. Revista Brasileira de Botânica, v.28, n.1, p.179-190, 2005.

LOCATELLI, E. M.; MACHADO, I. C. Fenologia de espécies arbóreas de uma Mata Serrana (Brejo de Altitude) em Pernambuco, Nordeste do Brasil. In: PORTO, K. C.; CABRAL, J. J.; TABARELLI, M. (Org.). Brejos de altitude em Pernambuco e Paraíba: história natural, ecologia e conservação. Brasília: Ministério do Meio ambiente, 2004. v.1. p.255-276.

LOPES, L. E.; BUZATO, S. Biologia reprodutiva de Psychotria suterella Muell. Arg. (Rubiaceae) e a abordagem de escalas ecológicas para a fenologia de floração e frutificação. Revista Brasileira de Botânica, v.28, n.4, p.785-795, 2005.

LORENZI, H. Árvores brasileiras: manual de identificação e cultivo de plantas arbóreas do Brasil. Nova Odessa: Instituto Plantarum, 2002. v.1. 384p.

MANTOVANI, M. et al. Fenologia reprodutiva de espécies arbóreas em uma formação secundária da floresta atlântica. Revista Árvore, v.27, n.4, p.451-458, 2003.

MARQUES, M. C. M.; OLIVEIRA, P. E. A. M. Fenologia de espécies do dossel e do sub-bosque de duas Florestas de Restinga na Ilha do Mel, sul do Brasil. Revista Brasileira de

Botânica, v.27, n.4, p.713-723, 2004.

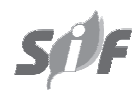

Revista Árvore, Viçosa-MG, v.37, n.1, p.129-136, 2013 
MELO, A. S. et al. Desenvolvimento vegetativo, rendimento da fruta e otimização do abacaxizeiro cv. Pérola em diferentes níveis de irrigação.

Ciência Rural, v.36, n.1, p.93-98, 2006.

MORELLATO, L. P. C. Sazonalidade e dinâmica de ecossistemas florestais na Serra do Japi. In: MORELlATO, L. P. C. (Org.). História

Natural da Serra do Japi: ecologia e preservação de uma área florestal no sudeste do Brasil. Campinas: UNICAMP, 1992. p.98-110.

MORELLATO, L. P. C.; LEITÃO-FILHO, H. F. Padrões de frutificação e dispersão na Serra do Japi. In: MORELLATO, L. P. C. (Org.).

História Natural da Serra do Japi: ecologia e preservação de uma área florestal no sudeste do Brasil. Campinas: UNICAMP, 1992. p.112-140.

PEDRONI, F.; SANCHEZ, M.; SANTOS, F. A. M. Fenologia da copaíba (Copaifera langsdorffii Desf. - Leguminosae, Caesalpinoideae) em uma floresta semidecídua no sudeste do Brasil.

Revista Brasileira de Botânica, v.25, n.2, p.183-194, 2002.

PIRES-O'BRIEN, M. J.; O'BRIEN, C. M. Ecologia e modelamento de florestas tropicais. Belém: FCAP, 1995. 400p.
REYS, P. et al. Fenologia reprodutiva e disponibilidade de frutos de espécies arbóreas em mata ciliar no rio Formoso, Mato Grosso do Sul. Biota Neotropica, v.5, n.2, p.309-318, 2005.

RICHARDS, P. W. The tropical rain forest. Cambridge: University Press, 1996. 575p.

SANTOS, D. L.; TAKAKI, M. Fenologia de Cedrela fissilis Vell. (Meliaceae) na região rural de Itirapina, SP, Brasil. Acta Botânica Brasílica, v.19, n.3, p.625-632, 2005.

SAN MARTIN-GAJARDO, I.; MORELLATO, L. P. C. Fenologia de Rubiaceae do sub-bosque em floresta Atlântica no sudeste do Brasil. Revista Brasileira de Botânica, v.26, n.3, p.299-309, 2003.

SOUZA, V. C.; LORENZI, H. Botânica sistemática: guia ilustrado para identificação das famílias de Angiospermas da flora brasileira, baseado em APG II. Nova Odessa: Instituto Plantarum, 2005. 640p.

van SCHAIK, C. P.; TERBORGH, J. W.; WRIGHT, S. J. The phenology of tropical forests: adaptive significance and consequences for primary consumers. Annual Review of Ecology and Systematics, v.24, p.353-377, 1993.

WRIGHT, S. J.; van SCHAIK, C. P. Light and the phenology of tropical trees. The American Naturalist, v.143, n.1, p.192-199, 1994. 